\title{
The Relation between Rumination and Emotional Reactions to Infidelity in Romantic Relationships
}

\author{
By Selin Onayli ${ }^{*}$ \\ Ozgur Erdur-Baker ${ }^{\dagger}$ \\ Panos Kordoutis
}

The purpose of this study is to examine the relationship between rumination and emotional reactions to infidelity. The sample of the study consisted of 72 participants from Turkey who reported being cheated on by their dating relationship. A Positive and Negative Affect Schedule (Watson et al. 1988) was used to measure the reactions to infidelity and the Ruminative Response Scale (Treynor et al. 2003) was used to measure rumination. Canonical correlation analyses were utilized to determine the relationships between rumination with the canonical variables of Brooding and Reflection and the emotional reactions to infidelity with the canonical variables of Positive Affect and the Negative Affect of participants. Results indicated that brooding and reflection, and negative and positive effects are interrelated. In other words, rumination is positively related with negative effects and negatively related with positive effects as reactions to infidelity.

Keywords: negative affect, positive affect, reactions to infidelity, rumination

\section{Introduction}

People pursue and maintain relationships in order to fulfill their belongingness need, however according to Blow and Harnett (2005), 25\% of relationships end with some form of romantic infidelity. According to Johnson (2003), the extent of infidelity is higher than what is reported. The terms, which are used to describe infidelity, are affair, cheating, unfaithfulness and betrayal (Wilson et al. 2011).Three types of infidelity were suggested, sexualonly, emotional-only, and combined sexual and emotional infidelity. Thompson (1984) and Özgün (2010) defined these types as follows: sexualonly is any kind of sexual contact such as intimate touching, kissing, or sexual intercourse; emotional-only is any kind of emotional attachment to another person, such as dating, flirting, or falling in love; and combined sexual and emotional is a combination of both of them. Glass and Wright (1985) described the types of infidelity on six-point as completely sexually, mostly sexually, more sexual than emotional, more emotional than sexual, mostly emotional,

${ }^{*}$ PhD Student, Middle East Technical University, Turkey.

${ }^{\dagger}$ Associate Professor, Middle East Technical University, Turkey.

tProfessor, Panteion University of Social and Political Sciences, Greece. 
and completely emotional. In dating relationships, prevalence of engaging in at least one type of infidelity behavior such as romantic kissing, dating or sexual activity is $75 \%$ for men and $68 \%$ for women (Wiederman and Hurd 1999). A more recent study by Allen and Baucom (2006) showed that $69 \%$ of the 504 university students experienced infidelity in the last two years. Statistical information about infidelity is very limited in Turkey; only the results of the 2005 Durex Global Sex Survey (Durex 2005) which was conducted in 41 countries provides statistical information. These results indicated that Turkey had the highest rate of infidelity with $58 \%$ of the survey participants reporting an extramarital sexual relationship.

Infidelity has an unclear role in society. Although it is considered an immoral act (Jankowiak et al. 2002, Treas and Gieson 2000), it is presented as an entertaining issue by media. Nevertheless, infidelity damages individuals and their relationships (Whisman et al. 1997). After discovering infidelity, very few couples have improved their relationship (Charny and Parnass 1995). Research suggesting that there are very limited positive outcomes of infidelity (Blow and Hartnett 2005); these include raising assertiveness, increasing the value of the family, increasing self-care and understanding the importance of marital communication according to Olson, Russell, Higgins-Kessler, and Miller's (2002) study on married couples who experienced infidelity. In terms of the negative outcomes of infidelity, depression has been frequently reported (Özgün 2010). Moreover, offended partners often use survival tactics and revenge which include anger and hostility combined with criticism, defensiveness (Blow 2005) and changeable emotions (Olson et al. 2002). Infidelity can be responsible for murder or suicide (Blow 2005) and serious emotional difficulties such as grief, depression, anxiety, hyper vigilance, obsessive rumination, and attachment trauma (Gordon et al. 2004). Therefore, examining emotional reactions to infidelity appears to be important.

Gender plays a significant role in infidelity (Atkins et al. 2001). Relationship dissatisfaction is the main reason for women's infidelity and sexual dissatisfaction is the main reason for men's infidelity (Allen et al. 2008, Whisman and Snyder 2007). Both types of infidelity may result in jealousy. Moreover, women and men show different reactions to infidelity (Shackelford et al. 2000). Sexual infidelity of the partner makes men more upset than women whereas emotional infidelity of the partner makes women more upset than men (Groothof et al. 2009). Gender difference in reacting infidelity was explained by the evolutionary theory and the sociocultural theory of jealousy (Wilson et al. 2011). The evolutionary theory claims that sexual infidelity is more difficult to handle for men, because men want generations with their genes. For women, it is more difficult to handle with emotional infidelity because they do not want to lose long term commitment and the resources of men to raise a child. On the other hand, according to sociocultural theory; men believe that women do not have sex without love and women believe that men can have sex without love (Harris and Christenfeld 1996). Therefore, an offended man partner thinks when his partner cheats on him sexually, it also means emotional infidelity. On the other hand, when a man cheats on his 
partner emotionally, the woman partner also thinks that sexual infidelity has happened as well (Wilson et al. 2011). Beyond gender and the type of infidelity, according to Wang et al. (2012), reactions to romantic infidelity differ; some people, who are constructive, try to solve the problems in their relationship, some people, who are passive, try to deny or avoid the situation, and some people behave revengefully, that is, they try to take a revenge or behave aggressively.

Several variables may impact how people react to infidelity and how they cope with it such as the discovery method of the infidelity (Afifi et al. 2001), and cognitive appraisal (Wang et al. 2012). The present study focuses on ruminative tendencies and its two subtypes called brooding and reflection. Rumination is known as a personality trait that puts individuals at risk of developing psychological problems when they are faced with a difficult life event. Therefore, examining rumination as a trait characteristic in the context of infidelity should help us understand the underlying reasons behind individual differences in reactions to infidelity. Rumination is a cycling thinking pattern which focuses on symptoms of distress in a passive and repetitive way and not on taking action to solve or correct the problems (Nolen-Hoeksema 1998). Ruminative people are more likely to have negative moods which trigger negative memories and decrease motivation to solve problems (Ward et al. 2003). Furthermore, rumination leads to having more maladaptive strategies to cope with distress (Lyubomirsky and NolenHoeksema 1995) and ruminators are known as pessimistic and reluctant in realizing plans (Ward et al. 2003). When humans experience a sad mood or a threatening event, they can ruminate on the meaning and the causes of those events and on the reasons to have negative moods. Also, they show negative thinking about themselves and their lives (Lyubomirsky and Nolen-Hoeksema 1995). Rumination has an important role on the intensification of negative affect and negative cognition and thereby, rumination has been found to be positively correlated with a negative mood (Moberly and Watkins 2008).

However, the latest research introduced two types of rumination; reflection and brooding which appear to be differently impacting individuals' coping with difficult life events. Treynor, et al. (2003) defined reflection as contemplation and pondering on personal shortcomings and life set-backs and brooding as anxious and gloomy thinking which involves efforts to analyze one's self, feelings, thoughts, and events. They found that reflection is less associated with depression; however, brooding is more associated with depression in a longitudinal analysis. Moreover, brooding is a more consistent predictor of depressive symptoms and is positively related with a negative mood; on the other hand, reflection is mostly associated with more adaptive outcomes, including reduction in depression symptoms and a negative relation with a negative mood over time (Treynor et al. 2003). If people with ruminative tendencies are more likely to have a pessimistic outlook and to blame themselves when they are faced with life difficulties such as infidelity, they should appraise the infidelity as a threat and thereby their reactions to infidelity should be rather negative. 
In sum, infidelity damages individuals and their relationships (Whisman et al. 1997). The partner offended by infidelity may be both cognitively and emotionally overwhelmed (Meldrim 2005). Although the impact of infidelity can be traumatic (Gordon and Baucom 1999), the scientific knowledge on infidelity and how to handle it is still somewhat limited. Also, who is more likely to react negatively among those with an infidelity experience is yet to be clarified. Therefore, ruminative tendencies as a cognitive risk factor were chosen to be tested in this study due to their reported relationships with several psychological variables as well as poor problem solving behavior. In other words, the present study aims to examine the relationship between the variables of rumination (brooding and reflection) and emotional reactions to infidelity (positive affect and negative affect). The expected result of the study is to find a significant relationship between rumination (brooding and reflection) and affective reactions to infidelity (positive affect and negative affect). The findings of the study should have particular implications for psychological counselors as relationship issues are common presenting problems among help seeking adult populations (Erdur-Baker and Bıçak 2006, Erdur-Baker et al. 2006).

\section{Method}

\section{Research Design}

Correlational research designs are appropriate for describing the relationships between two or more quantitative variables that have not been manipulated experimentally (Fraenkel and Wallen 2006). The present study is interested in describing such relationships; hence a descriptive/correlational research design has been employed.

\section{Participants \& Procedure}

Participants were recruited from Turkey by using convenience sampling. Participants were 210 (159 female, 51male) and their age varied between 18 and $49(M=28.77, S D=6.10)$. Only, seventy-two of them had experienced infidelity on their dating relationships, and consequently, all subsequent analyses concern these participants. More specifically, the 72 participants who were cheated on were 64 female and 8 male and their age varied between 19 and $42(M=28.61, S D=4.30)$.

The Research Center for the Applied Ethics Committee of METU approved the research prior to the online data collection. The purpose of the study was explained at the beginning of the questionnaires, which were administered to voluntary participants. Administration took approximately 5 minutes. 


\section{Instruments}

A demographic information form and two instruments were utilized: the Positive and Negative Affect Schedule (PANAS), and the Ruminative Response Scale (RRS).

\section{Demographic Information Form}

This form was designed by the researchers and included the following: gender, age, education level, discovery of the infidelity as the length of time since he/she discovered, if she/ he is currently with that partner, and description of the relationship his/her partner lived between sexual to emotional.

\section{Positive and Negative Affect Schedule (PANAS)}

The Positive and Negative Affect Schedule (PANAS) was developed by Watson, Clark, and Tellegen (1988). The PANAS has 20 items using a 5-point Likert-scale ( 1 "very slightly or not at all" to 5 "extremely") and is measuring a positive and negative effect. PANAS has 10 items on Positive Affect (PA), and 10 items on Negative Affect (NA) scales. The internal consistency of the Positive Affect subscale and Negative Affect subscales were found as 0.88 and 0.85 , respectively and test-retest reliability showed a correlation of 0.47 for both of the subscales. Gençöz (2000) translated and adapted the scale to Turkish. The internal consistency reliability of the Turkish version was found as 0.83 and 0.86 for PA, and NA, respectively. Test-retest reliability was 0.40 for PA, and 0.54 for the NA. In the current study, the Cronbach's alphas for the positive affect subscale and negative affect subscale were found as 0.82 for both of them.

\section{Ruminative Response Scale (RRS)}

The Ruminative Response Scale (RRS) was developed by NolenHoeksema and Morrow (1991); it is a subscale of the Response Style Questionnaire. The RRS is a 22-item, 4-point rating scale (1 "almost never" to 4 "almost always") which measures responses to depressed mood, symptoms or possible causes and consequences of their mood (Luminent, 2004). Treynor, Gonzalez, and Nolen-Hoeksema (2003) eliminated similar items in the Ruminative Responses Scale and suggested 10 items with 2 factors, brooding and reflection, each containing 5 items. The coefficient alpha of the Reflection subscale and the Brooding subscales were found as 0.72 and 0.77 , respectively and the test-retest reliability showed the correlation of 0.60 and 0.62 , respectively. The Turkish adaptation of the short version of the Ruminative Response Scale was conducted by Erdur-Baker and Bugay (2012). They reported Cronbach's alpha of the short version RRS as .85 and for the subscales as 0.77 and 0.75 . In the present study, the two factor (brooding and reflection) short version of the RRS was used. The Cronbach's alphas for the RRS were found as 0.87 ; for the brooding and reflection subscale were found as 0.76 and 0.80 , respectively. 


\section{Data Analysis}

Before conducting the main analysis, the missing values and assumptions of the Canonical Correlation Analysis were checked. In the first step of the analysis, the descriptive statistics were utilized to examine the characteristics of the sample and the variables of the study. The correlation coefficients among the variables were also examined. Then, to examine the main research question, which inquires about the relationships between emotional reactions to infidelity (positive and negative affect) and rumination (brooding and reflection), Canonical Correlation Analysis was conducted.

\section{Results}

Descriptive statistics indicated that out of the 72 participants who were cheated in their romantic relationship, $46(64 \%)$ were university students and $26(36.1 \%)$ were university graduates. Twenty-four $(33.4 \%)$ of the participants were informed that they were cheated on, less than 3 months ago, $14(19.4 \%)$ of them, 5 years ago and the other $33(45.8 \%)$ between 3 months to 5 years ago; $4(5.6 \%)$ of the participants are still with their partners who cheated on them. According to answers of the participants about how they describe the relationship of the partners lived; $7(9.7 \%)$ of them said completely sexually, $17(23.6 \%)$ of them said mostly sexually, 19 (26.4\%) of them said more sexual than emotional, 11 (15.3\%), of them said more emotional than sexual, 13 $(18.1 \%)$ of them said mostly emotional and $4(5.6 \%)$ of them said completely emotional. The mean score for the "brooding" subscale was $12.60(S D=3.63)$ while the mean score of the "reflection" subscale was $12.36(S D=3.53)$. The mean scores for the "positive affect subscale" and "negative affect" were $M=$ $27.74(S D=8.30)$ and $M=32.11(S D=8.19)$, respectively. Gender was not evaluated in any analysis because of the inadequate number of male participants. Analyses were repeated with and without male participants, yet similar results were revealed. The results with male participants were reported here.

The required assumptions of the canonical correlation analysis (missing data, outliers, multivariate normality, homoscedasticity, linearity, and multicollinearity) were examined and no gross violation was observed. Hence, a canonical correlation analysis was conducted to examine the relationship between rumination and reactions to infidelity. In this analysis, rumination variables are referred to as the independent variable set (IV set), comprising brooding and reflection. Reactions to infidelity variables, on the other hand, are regarded as the dependent variable set (DV set), consisting of a positive and negative affect. The results of the canonical correlation analysis are summarized in Table 1. 
Table 1. Correlations, Standardized Canonical Coefficients, Canonical Correlations, Percentages of Variance, and Redundancies between Rumination and Reactions to Infidelity Variables

\begin{tabular}{|c|c|c|}
\hline & \multicolumn{2}{|c|}{ First Canonical Variate } \\
\cline { 2 - 3 } & \multicolumn{2}{|c|}{ Correlations } \\
\hline Rumination & & \\
\hline Brooding & -0.99 & -0.90 \\
\hline Reflection & -0.79 & -0.13 \\
\hline Percentage of Variance & 0.80 & \\
\hline Redundancy & 0.23 & \\
\hline Reactions to Infidelity & & 0.12 \\
\hline Positive Affect & 0.39 & -0.96 \\
\hline Negative Affect & -0.99 & \\
\hline Percentage of Variance & 0.57 & \\
\hline Redundancy & 0.16 & \\
\hline Canonical Correlation & 0.54 & \\
\hline
\end{tabular}

There are two results of the canonical correlation for the sample. As Hair, Anderson, Tatham, and Black (2006) suggested the canonical coefficient which is greater than 0.30 is taken into consideration. The first canonical coefficient is greater than 0.30 and is 0.54 (29\% overlapping the variance); therefore, it is significant and has been used to explain the results $(p<.05)$. The rumination variables are significantly correlated with the reactions to infidelity variables $\left(\chi^{2}(4)=23.25, p=.00\right)$ in the first canonical variate. Therefore, the first canonical variate accounts for the significant relationships between the two sets of variables.

With a cut of correlation of 0.30 (Tabachnick and Fidell, 2007) the rumination set indicates that it is correlated with the first set of variables which are brooding (-0.99), and reflection $(-0.79)$. The variables in the reactions to infidelity set shows that reactions to infidelity are correlated with the second set of variables which are a positive affect (0.39) and negative affect $(-0.99)$. The canonical loadings for the factors of rumination and reactions to infidelity are higher than 0.30 and prove that the change in the brooding and reflection is significantly parallel to the change in positive and negative affect (Figure 1).

The "Percent of Variance" values are used to evaluate the strength of the relation between a variate of the equation and the variables on the same side. The percentage of values shows that the first set of variables explains $80 \%$ of the rumination and the second set of variables explains $57 \%$ of the reactions to infidelity variables.

The "Redundancy" values are used to evaluate the strength of the relation between a variate of the equation and variables on the other side. The redundancy values, $23 \%$ of the total variance of rumination is clarified by all of the reactions to infidelity; and $16 \%$ of the total variance of reactions to infidelity variables has been explained with all of the rumination variables. 
Figure 1. Relationships among Variables and Canonical Variates

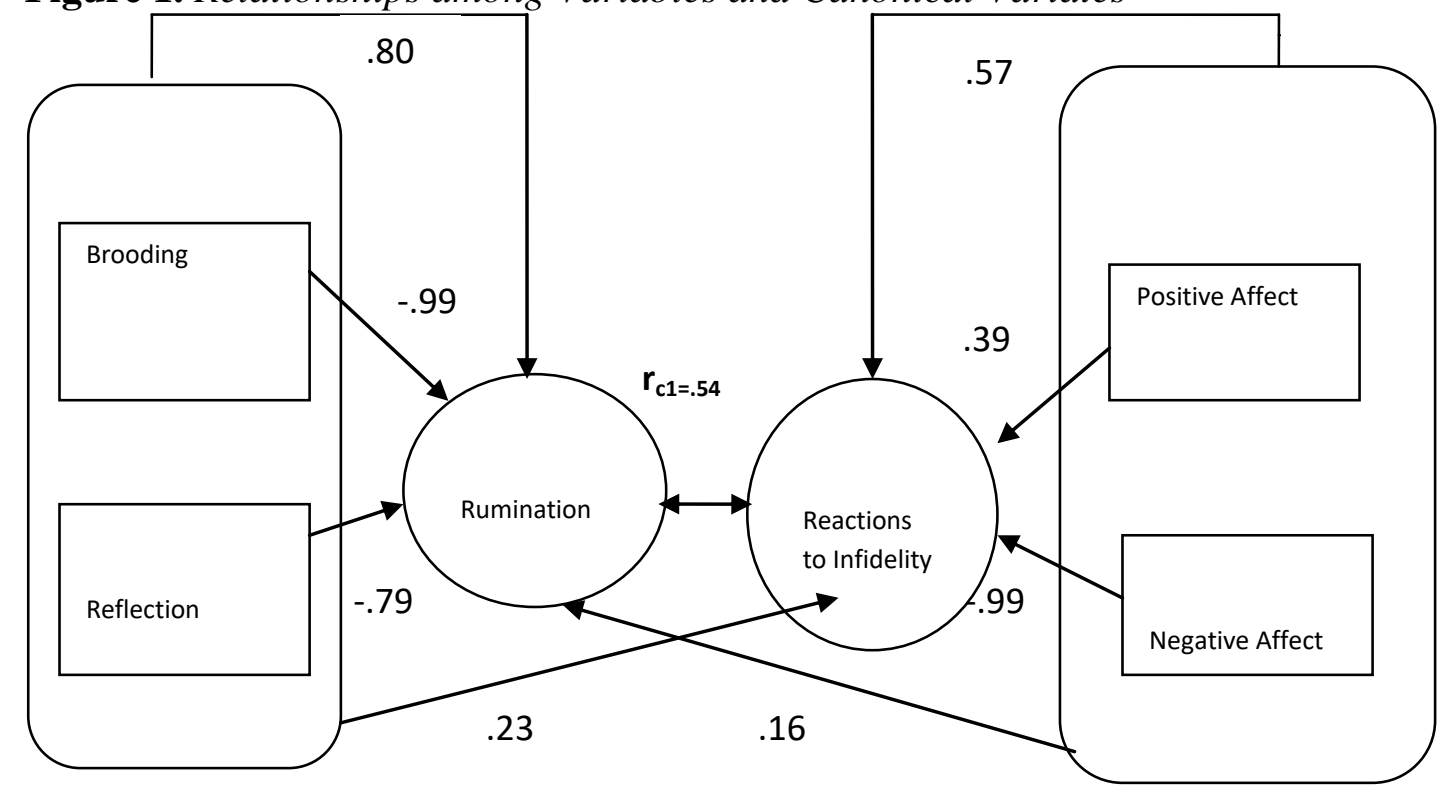

\section{Discussion and Conclusion}

This study examined the relationships between the emotional reactions to infidelity (positive and negative affect) and ruminative tendencies (brooding and reflection) in a Turkish sample that were cheated during dating relationships. The results of the canonical correlation analysis indicated that the actions to the infidelity variable set and the rumination variable set are correlated with each other. Examining the relationships on the bases of the dimensions of the main variables, revealed that negative and positive effects are all associated with emotional reactions to infidelity and they are also related with the brooding and reflection which are in the set of rumination. Furthermore, brooding and reflection are all associated with rumination and they are also related with negative and positive affects as a reaction to infidelity. Among two variables, brooding has the greatest contribution on the rumination variable set. Brooding and reflection strongly contribute to negative affects as are action to infidelity. Negative effects have a great contribution on the reactions to infidelity set. However, the positive affect is not highly correlated like the other variables and as it was expected it has a negative relationship with variables which are brooding, reflection and a negative effect. In brief, when brooding and reflection decrease, the negative affect decreases too, while on the other hand, the positive affect increases.

When ruminative people are faced with difficulties such as infidelity, they see it as a threat and both negative mood and negative affect rise. It was expected to find a negative relationship between positive affect and rumination because the ruminative people are more likely to have negative moods (Ward 
et al. 2003) and to focus on negative affect and on negative cognition (Moberly and Watkins 2008). Moreover, brooding is positively related with a negative mood (Treynor et al. 2003) and this explains the high contribution of brooding to negative reactions. Reflection is relatively more adaptive with a negative mood over time (Treynor et al. 2003). In the present study, this could be the reason why reflection does not contribute to negative reactions as highly as brooding. On the other hand; it should be said that $33.4 \%$ of the participants were informed that they were cheated, less than 3 months ago; hence, one could expect that the reflection scores might change over time.

The results of this study can be beneficial to couples, families and professionals in the mental health area. It may be useful for professionals, in the field of psychological counseling, to more fully understand how rumination is related with a person's reactions to romantic infidelity. This understanding, in turn, may help in improving treatments pertinent to romantic infidelity, thus assisting couples before and after experiencing infidelity. Furthermore, handling with rumination can be prevention. The ruminative people can be recognized from repeatedly thinking about self and past events. They are repetitively and passively focused on symptoms of distress (Nolen-Hoeksema et al. 2008) "why did this happen to me?", or "why can I not handle better with that situation?" are examples of questions that ruminative people ask themselves. Cognitive Behavior Therapy can be useful to a professional to help his/her client to handle with rumination (e.g. Şenormanc1 et al. 2013, Wilkinson and Goodyer 2008). Moreover, according to Purdon's (2004) newer models as mindfulness-based cognitive therapy, attention training treatment, and new cognitive models will be helpful to handle rumination. Given that family, marriage and pre-marriage counseling is one of the most rapidly emerging areas of counseling, mental health professionals working in this area, are in great need of scientific knowledge deriving specifically from the empirical study of relationship phenomena, so that therapeutic skills can be developed accordingly.

The present study has several limitations. The convenient sampling method, the small number of male participants and a sample only from Turkey limit the generalizability of the results. In addition, self-report measures involve social desirability problems that might have affected the results.

To amend the above limitations future research should aim for greater generalizability, by employing a larger sample with a more or less equal number of men and women. Generalizability could also be improved by using a random sampling method for collecting data, along with an alternative to online administration procedure. To counter social desirability effects, commonly associated with such sensitive issues as cheating, and in order to extract richer information, alternative to the self-report methods should be employed, such as focus-groups of people who have been cheated on or indepth interviews with them, followed by content analyses. Finally, crosscultural comparisons could help us understand what are the broader, macrosocietal factors (such as religion, social values, urban living, socioeconomic status and education), that might contribute to people's reactions to infidelity. 


\section{References}

Afifi WA, Falato WL, Weiner JL (2001) Identity concerns following a severe relational transgression: The role of discovery method for the relational outcomes of infidelity. Journal of Social and Personal Relationship 18(2): 291-308. Retrieved from http://dx.doi.org/10.1177/0265407501182007.

Allen ES, Baucom DH (2006) Dating, marital, and hypothetical extradyadic involvements: How do they compare? The Journal of Sex Research 43(4): 307317. Retrieved from http://dx.doi.org/10.1080/00224490609552330.

Allen ES, Klinerhoades G, Stanley S, Markman HJ, Williams T, Melton J, Clements M (2008) Premarital precursors of marital infidelity. Family Process 47: 243259. Retrieved from http://dx.doi.org/10.1111/j.1545-5300.2008.00251.x.

Atkins DC, Baucom DH, Jacobson NS (2001) Understanding infidelity: Correlates in a national random sample. Journal of Family Psychology 15: 735-749. Retrieved from http://dx.doi.org/10.1037/0893-3200.15.4.735

Blow AJ (2005) Face it head on: Helping a couple move through the painful and pernicious effects of infidelity. Journal of Couple \& Relationship Therapy 4(2/3): 91-102. Retrieved from http://dx.doi.org/10.1300/J398v04n02_09

Blow AJ, Hartnett K (2005) Infidelity in committed relationships: II. A substantive review. Journal of Marital and Family Therapy 31: 217-233. Retrieved from http://dx.doi.org/10.1111/j.1752-0606.2005.tb01556.x

Charny IW, Parnass S (1995) The impact of extramarital relationships on the continuation of marriages. Journal of Sex \& Marital Therapy 21: 100-115. Retrieved from http://dx.doi.org/10.1080/00926239508404389

Durex (2005) The 2005 Durex Global Sex Survey. Retrieved from http://bit.ly/19nNSRT

Erdur-Baker Ö, Aberson C, Drapper M, Barrow J (2006) Nature and severity of college students' psychological concerns: A comparison of clinical and nonclinical national samples. Professional Psychology: Research and Practice 37: 317-323. Retrieved from http://dx.doi.org/10.1037/0735-7028.37.3.317

Erdur-Baker Ö, Bıçak B (2006) Üniversite öğrencilerinin psikolojik sorunları. [Psychological issues among university students]. A.İ.B. Ü. Ĕgitim Fakültesi Dergisi 6: $54-66$.

Erdur-Baker Ö, Bugay A (2012) The Turkish version of the Ruminative Response Scale: An examination of its reliability and validity. The International Journal of Educational and Psychological Assessment 10(2): 1-16. Retrieved from http:// dx.doi.org/10.1016/j.sbspro.2010.07.433.

Fraenkel JR, Wallen NE (2006) How to design and evaluate research in education. Boston: McGraw-Hill.

Gençöz T (2000) Pozitif ve Negatif Duygu Durum Ölçeği: Geçerlik ve güvenirlik çalışması [Positive and Negative Affect Schedule: A study of validity and reliability]. Türk Psikoloji Dergisi 15(46): 19-28.

Glass SP, Wright TL (1985) Sex differences in type of extramarital involvement and marital dissatisfaction. Sex Roles 12: 1101-1120. Retrieved from http://dx.doi.org/10.1007\%2FBF00288108.

Gordon KC, Baucom DH (1999) A multitheoretical intervention for promoting recovery from extramarital affairs. Clinical Psychology: Science and Practice 6: 382-399. Retrieved from http://dx.doi.org/10.1093/clipsy.6.4.382.

Gordon KC, Baucom DH, Snyder DK (2004) An integrative intervention for promoting recovery from extramarital affairs. Journal of Marital and Family 
Therapy 30(2): 213-231. Retrieved from http://dx.doi.org/10.1111/j.17520606.2004.tb01 235.x.

Groothof HAK, Dijkstra P, Barelds DPH (2009) Sex differences in jealousy: The case of internet infidelity. Journal of Social and Personal Relationships 26(8): 11191129. Retrieved from http://dx.doi.org/10.1177/026540750934 8003.

Hair JF, Anderson RE, Tatham RL, Black WC (2006) Multivariate Data Analysis (5th ed.). Upper Saddle River, NJ: Prentice Hall.

Harris CR, Christenfeld N (1996) Gender, jealousy, and reason. Psychological Science 7(6): 364-366. Retrieved from http://dx.doi.org/10.1111/j.1467-9280. 1996.tb00390.x.

Jankowiak W, Nell MD, Buckmaster A (2002) Managing infidelity: A crosscultural perspective. Ethnology 41(1): 85-101. Retrieved from http://dx.doi.org/10. $2307 / 4153022$.

Johnson S (2003) The trent lott affair. Journal of Feminist Family Therapy: An International Forum 15(1): 73-75. Retrieved from http://dx.doi.org/10.1300/ j086v15n 01_06.

Luminet O (2004) Assessment and measurement of rumination. In C. Papageorgiou and A. Wells (Eds.), Rumination: Nature, theory, and treatment of negative thinking in depression, 187-215. Chichester, England: Wiley.

Lyubomirsky S, Nolen Hoeksema S (1995) Effects of self-focused rumination on negative thinking and interpersonal problem-solving. Journal of Personality and Social Psychology 69(1): 176-190. Retrieved from: http://dx.doi.org/10.1037/ 0022-3514. 69.1.176.

Meldrim HL (2005) The impact of infidelity on the offended spouse: A study of gender differences and coping strategies in a religious population. Unpublished dissertation, Syracuse University, New York.

Moberly NJ, Watkins ER (2008) Ruminative self-focus and negative affect: An experience sampling study. Journal of Abnormal Psychology 117(2): 314-323. Retrieved from http://dx.doi.org/10.1037/0021-843x.117.2.314.

Nolen-Hoeksema S (1998) The other end of the continuum: The costs of rumination. Psychological Inquiry 9(3): 216-219. Retrieved from http://dx.doi.org/10.1207/ s15327 965pli0903_5.

Nolen-Hoeksema S, Morrow J (1991) A prospective study of depression and posttraumatic stress symptoms after a natural disaster: The 1989 Loma Prieta Earthquake. Journal of Personality and Social Psychology 61(1): 115-121. Retrieved from http://dx.doi.org/10.1037/0022-3514.61.1.115.

Nolen-Hoeksema S, Wisco, BE, Lyumbomirsky S (2008) Rethinking rumination. Perspectives on Psychological Science 3(5): 400-424. Retrieved from http://dx.doi.org/10.1111/j.1745-6924.2008.00088.x

Olson MM, Russell CS, Higgins-Kessler M, Miller RB (2002) Emotional processes following disclosure of an extramarital affair. Journal of Marital and Family Therapy 28(4): 423-434. Retrieved from http://dx.doi.org/10.1111/j.1752-0606. 2002.tb00367.x

Özgün S (2010) The predictors of the traumatic effect of extramarital infidelity on married women: coping strategies, resources, and forgiveness. Unpublished dissertation, Middle East Technical University, Ankara.

Purdon C (2004) Psychological treatment of rumination. In C Papageorgiou, A Wells (Eds), Depressive Rumination: Nature, Theory and Treatment, 217-239. Chichester, England: Wiley 
Shackelford TK, LeBlanc GJ, Drass E (2000) Emotional reactions to infidelity. Cognition and Emotion 14(5): 643-659. Retrieved from http://dx.doi.org/10.10 80/02699930050117657.

Şenormancı Ö, Konkan R, Güçlü O, Şenormancı G, Sungur MZ (2013) The relationship between dysfunctional attitudes, rumination response styles and depression. Düşünen Adam: The Journal of Psychiatry and Neurological Sciences 26(3): 239-247. Retrieved from: http://dx.doi.org/10.5350/DAJPN 2013260302.

Tabachnick BG, Fidell LS (2007) Using Multivariate Statistics (5th Ed.). Boston: Pearson Education Company.

Thompson AP (1984) Emotional and sexual components of extramarital relations. Journal of Marriage and the Family 46(1): 35-42. Retrieved from http://dx.doi.org/10.2307/351861.

Treas J, Giesen D (2000) Sexual infidelity among married and cohabiting. Americans Journal of Marriage and the Family 62(1): 48-60. Retrieved from: http://dx. doi.org/10.1111/j.1741-3737.2000.00048.x.

Treynor W, Gonzalez R, Nolen-Hoeksema S (2003) Rumination reconsidered: A psychometric analysis. Cognitive Therapy and Research 27(3): 247-259. Retrieved from http://dx.doi.org/0147-5916/03/0600-0247/0.

Wang CD, King ML, Debernardi NR (2012) Adult attachment, cognitive appraisal, and university students' reactions to romantic infidelity. Journal of College Counseling 15(2): 101-116. Retrieved from http://dx.doi.org/10.1002/j.21611882. 2012.00009.x.

Ward A, Lyubomirsky S, Sousa L, Nolen-Hoeksema S (2003) Can't quite commit: Rumination and uncertainty. Society for Personality and Social Psychology 29(1): 96-107. Retrieved from http://dx.doi.org/10.1177/0146167202238375.

Watson D, Clark LA, Tellegen A (1988) Development and validation of brief measures of positive and negative affect: The PANAS scales. Journal of Personality and Social Psychology 54(6): 1063-1070. Retrieved from http://dx. doi.org/ 10.1037/0022-3514.54.6.1063.

Whisman MA, Dixon AE, Johnson S (1997) Therapists' perspectives of couple problems and treatment issues in couple therapy. Journal of Family Psychology 11(3): 361-366. Retrieved from http://dx.doi.org/10.1037//0893-3200.11.3.361

Whisman MA, Snyder KS (2007) Sexual infidelity in a national survey of American women: Differences in prevalence and correlates as a function of method of assessment. Journal of Family Psychology 21(2): 147-154. Retrieved from http://dx.doi.org/10.1037/0893-3200.21.2.147.

Wiederman M, Hurd C (1999) Extradyadic involvement during dating. Journal of Social and Personal Relationships 16(2): 265-274. Retrieved from http://dx.doi. org/10. 1177/0265407599162008.

Wilkinson PO, Goodyer IM (2008) The effects of cognitive-behavioural therapy on mood-related ruminative response style in depressed adolescents. Child and Adolescent Psychiatry Mental Health 2(1): 3. Retrieved from http://dx.doi.org/10.1186/1753-2000-2-3.

Wilson K, Mattingly BA, Clark EM, Weidler DJ, Bequette AW (2011) The Gray Area: Exploring Attitudes Toward Infidelity and the Development of the Perceptions of Dating Infidelity Scale. The Journal of Social Psychology 151(1): 63-86. Retrieved from http://dx.doi.org/10.1080/00224540903366750. 